\title{
ACCESO A LA JURISDICCIÓN CONTENCIOSO ADMINISTRATIVA
}

\author{
Marianella Ledesma NarVAeZ*
}

\begin{abstract}
Resumen
Desde una visión clásica de la jurisdicción contencioso administrativa, ésta se halla orientada a conocer todas aquellas pretensiones deducidas por los administrados contra los actos de la administración pública sujetos al derecho administrativo; sin embargo, esta tradicional concepción se ha venido superando a favor de concebirla como vía para una verdadera y adecuada tutela jurisdiccional efectiva de los derechos e intereses legítimos de los ciudadanos frente a cualquier acto ilícito de la administración pública, lo que ha generado el incremento del traslado de la discusión de sede administrativa a sede judicial, en atención a que las pretensiones contenciosas no están en función del acto administrativo ni tampoco están condicionadas al contenido de dicho acto, y por tanto, el centro de gravedad en el contencioso administrativo ya no es el acto administrativo en sí, sino los intereses subjetivos de los ciudadanos que se enfrentan a la administración pública.
\end{abstract}

Palabras clave: Jurisdicción contencioso administrativa - Tutela jurisdiccional efectiva - Silencio administrativo.

\begin{abstract}
In classical terms, the administrative-adversary jurisdiction is aimed at hearing all claims filed by claimants against acts of the government administration subject to Administrative Law. However, this traditional concept has been superseded in favor of conceiving it as a channel for a true and suitable effective jurisdictional protection of the legitimate rights and interests of citizens facing any unlawful act committed by the government administration. This fact has produced an increase in the transfer of discussion from the administrative venue to the judicial venue, since adversary proceedings do not refer to administrative acts nor are they conditioned to the contents of said acts and consequently, the center of gravity in the administrative adversary dispute is no longer the administrative act itself but the subjective interests of the citizens that confront the government administration.
\end{abstract}

Key words: Administrative-adversary jurisdiction - Effective jurisdictional protection - Administrative silence.

\section{Sumario}

1. Introducción. 2. Naturaleza y características del proceso contencioso administrativo. 3. El silencio administrativo administrativo y la potestad jurisdiccional. 4. La tutela jurisdiccional efectiva de los derechos de los administrados - Tendencias actuales en el distrito judicial de Lima. 5. Conclusiones.

\footnotetext{
* Juez Civil Supernumerario de Lima - Poder Judicial de Perú. Profesora de la Pontificia Universidad Católica del Perú.
} 


\section{INTRODUCCIÓN}

Tradicionalmente se ha sostenido que la jurisdicción contencioso administrativa conoce de las pretensiones que se deduzcan en relación a los actos de la administración pública sujetos al derecho administrativo y las disposiciones reglamentarias. Esto llevaba a destacar el carácter revisor de la jurisdicción contencioso-administrativa, se afirmaba que, la jurisdicción debía ceñirse a las cuestiones resueltas por el acto previo de la administración, sin que sea posible variar las pretensiones formuladas en vía administrativa, toda vez que la jurisdicción debe examinar el acto previo, para analizarlo a la luz del ordenamiento jurídico.

Bajo ese marco se entendía el carácter revisor del contencioso que suponía que los jueces tenían que limitarse a enjuiciar la validez del acto impugnado y debían hacerlo, además, bajo la pausa previamente establecida en la fase administrativa, como si se tratase de un recurso de impugnación contra una sentencia. Esto implicaba que no se podían pronunciar sobre cuestiones no planteadas formalmente en la vía administrativa o respecto de las que la administración no se hubiese pronunciado expresamente, ni se podía practicar prueba salvo para revisar la practicada en el expediente administrativo. El carácter revisorio estaba limitado al contenido del acto administrativo impugnado, caso contrario, suponía una invasión de la competencia de la actividad administrativa. Había un privilegio en la administración que le permitía exigir que cualquier discrepancia con sus decisiones se ventile en sede administrativa ante sus propios órganos jerárquicos superiores, como condición previa a la interposición de la demanda judicial. Esta especial condición se distorsionaba por una práctica orientada a dilatar el agotamiento de la vía administrativa, de tal manera que se evitaba que la decisión cause estado, limitando así el derecho a hacer valer la tutela judicial efectiva. En otras palabras, bastaba que la actividad administrativa no sea diligente en su pronunciamiento para que toda la secuencia del procedimiento se paralizare y con mayor razón el control jurisdiccional no prospere.

La tradicional y restringida concepción del recurso contencioso-administrativo como una revisión judicial de actos administrativos previos, ha sido superada - pero no abandonada- para abrir definitivamente las puertas a cualquier comportamiento ilícito de la administración. Ahora bien, no es que se haya desterrado la revisión por completo de la esfera de la actividad jurisdiccional, sino que se admite la posibilidad de que también se brinde tutela al particular de situaciones jurídicas del cual es titular. Esto evidentemente ha tenido una repercusión sobre el proceso contencioso administrativo, que como señala 
Priori ${ }^{1}$ "ha sufrido un importantísimo desarrollo en su concepción, pues, se ha pasado de un proceso en el cuál solo era posible que el órgano jurisdiccional realice una revisión de legalidad del acto, como expresión del sistema francés de "exceso de poder", a un proceso contencioso administrativo que brinda una tutela efectiva a situaciones jurídicas de los justiciables, es decir, una real y efectiva tutela, la misma que va más allá del solo control de legalidad del acto administrativo".

La necesidad de que antes de acudir a dicha jurisdicción exista un acto administrativo, no significa que se haya querido concebir a la jurisdicción contencioso administrativa como una segunda instancia; por el contrario, se sigue un auténtico proceso entre partes, cuya misión es examinar las pretensiones que deduzca la parte actora por razón de un acto administrativo, la misma que no puede quedar condicionada por el contenido del acto objeto de impugnación, porque de lo contrario, la administración podría limitar u obstaculizar el ejercicio de la potestad jurisdiccional, y en consecuencia, basta el hecho que la administración haya tenido la oportunidad de pronunciarse sobre el fondo del tema discutido para que se estime cumplido el principio de contradicción y, en consecuencia, debe el juez en lo contencioso resolver el fondo del asunto, siempre que existan elementos de juicio suficientes para ello. En otras palabras, la intervención de la jurisdicción contencioso administrativa, supone ofrecer a la administración la posibilidad de pronunciarse sobre las cuestiones planteadas, y nada más. Si la administración no se pronuncia, o no lo hace sobre todas las cuestiones, ello no debe limitar el debate procesal en vía jurisdiccional. Lo único que se exige, es que a la administración, previamente a lo jurisdiccional, se le haya dado la oportunidad de resolver las mencionadas pretensiones en sede administrativa. Ante ello, en el proceso contencioso administrativo se pueden plantear dos tipos de pretensiones, la de anulación o de nulidad y la plena jurisdicción.

En conclusión, la visión clásica de la jurisdicción contencioso administrativa se orientaba a conocer de las pretensiones que se deducían en relación a los actos de la administración pública sujetos al derecho administrativo y con las disposiciones reglamentarias. De ahí que el carácter revisor del contenciosoadministrativo, asume como regla general, ceñirse a las cuestiones resueltas por el acto previo de la administración, sin que sea posible variar las pretensiones formuladas en vía administrativa, toda vez que - como se ha dicho - la jurisdicción debe examinar el acto previo, para analizarlo a la luz del ordenamiento jurídico ${ }^{2}$; sin embargo, esta tradicional y restringida concepción del recurso contencioso-administrativo - entendido como una revisión judicial de actos administrativos previos - se ha superado para abrir 
las puertas del contencioso administrativo frente a cualquier comportamiento ilícito de la administración.

\section{NATURALEZA Y CARACTERÍSTICAS DEL PROCESO CONTENCIOSO ADMINISTRATIVO}

El proceso contencioso administrativo tiene una base constitucional en el artículo $148^{\circ}$ de la Constitución del Estado, que reproduce la vieja regulación del artículo $240^{\circ}$ de la Constitución de 1979. Textualmente dice el artículo $1481^{\circ}$ de la Constitución: "Las resoluciones administrativas que causan estado son susceptibles de impugnación mediante la acción contenciosoadministrativa".

De su redacción se puede colegir el carácter revisor de la jurisdicción contencioso administrativa, emitiendo el aparente mensaje de que dichos procesos deberían limitarse únicamente a la revisión judicial de los actos administrativos; sin embargo, no se debe olvidar que el proceso contencioso administrativo expresa la función jurisdiccional del Estado y como tal viabiliza el derecho a la tutela judicial efectiva, consagrada en el artículo 139.3 de la Constitución; no obstante, todavía se encuentran algunos pronunciamientos judiciales que sostienen que para que pueda prosperar una pretensión siempre es necesaria la existencia previa del acto administrativo y que aquella se deduzca precisamente en relación al mismo, pues, la lectura literal del artículo $148^{\circ}$ de la Constitución así lo establece.

En contraposición a ello, Huayapa ${ }^{3}$ afirma que el proceso contencioso administrativo es un medio jurisdiccional destinado a brindar tutela a los derechos subjetivos del ciudadano y de su posición central en el ordenamiento jurídico; este proceso es parte de los postulados del Estado de derecho, en la medida que constituye un instrumento destinado a efectivizar el control interorgánico de la administración pública; y es un medio que permite garantizar la tutela judicial efectiva frente a todo acto del poder administrativo que vulnere o dañe un derecho subjetivo o un interés legítimo de un sujeto de derecho. En esa misma línea aparece la opinión de Priori" "si la Constitución de 1993 consagraba el derecho a la tutela jurisdiccional efectiva, el proceso contencioso administrativo no solo debía procurar el control del acto administrativo, sino que debía brindar una efectiva tutela a las situaciones jurídicas de los particulares".

Por nuestra parte sostenemos que la constitucionalidad del contencioso administrativo no se satisface en la mera lectura del artículo $148^{\circ}$ de la Cons- 
titución, que afirma el carácter revisorio - a través de la impugnación - de la jurisdicción contencioso administrativa, sino en una apreciación de otros referentes como el derecho a la tutela judicial efectiva, la misma que no puede ser comprometida y obstaculizada mediante la imposición de formalismos enervantes o acudiendo a interpretaciones de las normas que regulan las exigencias formales del proceso claramente desviadas del sentido propio de la tutela judicial; además, las normas reguladoras de los requisitos procesales deben interpretarse siempre en el sentido más favorable a la admisión de las pretensiones, pues, el acceso a la jurisdicción no debe limitarse por formalidades procesales, ellas han de ser razonables y proporcionadas en relación con el objetivo pretendido y no han de afectar al contenido esencial del derecho.

Hay que afirmar el carácter accesorio o instrumental del acto previo en el proceso contencioso administrativo frente al carácter principal y determinante de la pretensión procesal. En opinión de García 5 , "el proceso contencioso administrativo ya no puede ser concebido como un cauce jurisdiccional para la protección de la sola legalidad objetiva o, si se prefiere, como un proceso al acto, sino, fundamentalmente, como una vía jurisdiccional para la efectiva tutela de los derechos e intereses legítimos de la administración y de los administrados; no tiene por qué tener siempre un carácter exclusivamente revisor" 6 .

Para Priori ${ }^{7}$, la nueva visión del contencioso administrativo tiene cuatro notas caracterizadoras: “i) tiene el derecho a la tutela jurisdiccional efectiva como el eje central de su contenido; ii) propicia un proceso contencioso administrativo tuitivo a favor de los particulares; iii) establece un proceso contencioso administrativo de "plena jurisdicción" o "subjetivo"; pues, predica un control jurisdiccional pleno de los actos administrativos que no se restringe a su solo control de legalidad, sino un control que supone brindar una efectiva tutela a los derechos e intereses de los administrados; iv) concibe al proceso contencioso administrativo como un proceso distinto y autónomo respecto del proceso civil, pues, la naturaleza de los conflictos que está llamado a resolver es absolutamente distinta a la naturaleza de los conflictos que está llamado a resolver el proceso civil".

Aun más, los detractores de esta visión del contencioso administrativo afirman que la falta de un previo planteamiento en la vía administrativa provoca indefensión de la administración, sin embargo, la indefensión se afirma cuando se priva al interesado de la posibilidad de impetrar la protección jurisdiccional de sus derechos o intereses mediante la apertura del adecuado proceso o de realizar dentro de dicho proceso las adecuadas alegaciones y 
pruebas o, finalmente, cuando se crea un obstáculo que dificulta gravemente las actividades antedichas. No hay indefensión para quien voluntariamente, por sus propios actos, se coloca en dicha posición, como normalmente hace la administración al incumplir el ordenamiento jurídico infringiendo los deberes legalmente establecidos, cual es el de resolver las peticiones que le dirijan los administrados o comunicar los recursos que contra sus resoluciones puedan darse.

En conclusión, sostenemos que el ciudadano ya no tiene que limitarse a reaccionar frente a la actuación administrativa, ni el contencioso administrativo tiene por qué concebirse como un medio de estricto control de la legalidad de aquella actuación. El sistema procesal administrativo debe cambiar su centro de gravedad, hasta ahora determinado por referencia a los actos de la administración y debe configurarse en torno a los intereses subjetivos de los ciudadanos, para lo cual, se pasa por concebir un sistema plural o abierto de pretensiones procesales, que permita afirmar distintas vías aptas para el resarcimiento de las diferentes necesidades de protección jurídica. De forma que, surgido el conflicto, los jueces se limiten a determinar cuál es la concreta necesidad del litigante, cuál su reclamación, cuál en definitiva su pretensión.

La jurisprudencia ha previsto mecanismos para superar los obstáculos que el mantenimiento de esta regla pudiera suponer al pleno ejercicio del derecho constitucional a la tutela judicial efectiva, como la que aparece en el siguiente caso de remisión de lo actuado a la vía contencioso administrativa, frente a la omisión de la administración en expedir la licencia de funcionamiento solicitada. El Tribunal Constitucional ha dicho:

"Teniendo en cuenta que la recurrente alega haber cumplido con todos los requisitos para obtener la licencia de funcionamiento solicitada, y que, pese a ello, la administración edil de manera arbitraria no expide dicho documento, este Colegiado considera, de conformidad con el criterio vertido en el fundamento $\mathrm{N}^{\circ} 7$, supra, que la presente demanda debe ser encausada a la vía contencioso-administrativa, la cual, para dirimir la controversia, cuenta con una adecuada estación para actuar los elementos probatorios presentados por las partes" ${ }^{8}$.

Aun más, el Tribunal Constitucional ha establecido que tomando en consideración que la demanda debe derivarse a la vía contencioso administrativa, son aplicables al presente caso, mutatis mutandis, las reglas procesales establecidas en los fundamentos $\mathrm{N}^{\circ} 53$ a 58 de la STC $\mathrm{N}^{\circ} 1417-2005-$ PA, publicada en el diario oficial "El Peruano" el 12 de julio de 20059. 
Estos pronunciamientos nos inducen a reconsiderar la funcionalidad de la vía previa como requisito de procedibilidad. Todas ellas pasan por centrar el objeto del contencioso no en el acto, sino en las pretensiones que se deduzcan en relación con dicho acto, criterio éste mucho más amplio; por lo que se debe colegir que el proceso contencioso administrativo, tiene como razón de ser, garantizar la tutela judicial efectiva a derechos e intereses legítimos de los ciudadanos, y eso es precisamente lo que da a esta jurisdicción su esencial carácter subjetivo, eliminando de raíz la vieja idea en torno a su naturaleza meramente revisora, pese a que tenga una referencia constitucional al respecto.

\section{EL SILENCIO ADMINISTRATIVO Y LA POTESTAD JURISDIC- CIONAL}

El contenido del acto administrativo no puede condicionar el ámbito de la potestad judicial, por ello una vez que se ha producido en la realidad o en la ficción (a través del silencio administrativo) y cualquiera que fuesen los pronunciamientos de la administración, los jueces tienen vía libre y jurisdicción plena para juzgar todas las cuestiones planteadas.

La práctica habitual de la administración de abstenerse de pronunciarse o de no actuar expresamente, pese a la obligación de resolver, encontró su contrapeso en la ficción jurídica del silencio administrativo, tal y como aparecía regulado en la Ley del Procedimiento Administrativo General (LPAG) $N^{\circ} 27444$ y la Ley de Silencio Administrativo N²9060.

La ley sustituye por sí misma la voluntad inexistente de la administración, presumiendo que para determinados efectos, dicha voluntad se ha producido y tiene un determinado contenido positivo o negativo. Conforme sostiene el Tribunal Constitucional, el silencio administrativo constituye un privilegio del administrado frente a la administración para protegerlo ante la eventual mora de esta en resolver su petición, pues quien incumple el deber de resolver no debe beneficiarse de su propio incumplimiento"10. Para García ${ }^{11}$, "a fin que los particulares no resultasen perjudicados por el incumplimiento de la administración de su obligación de resolver, topándose con el acceso a la jurisdicción vedado por faltar el requisito del acto previo, el ordenamiento jurídico articuló un sistema que generalizaba el control jurisdiccional de toda la actividad administrativa expresa o presunta, que consistía, respecto de esta última, en entender desestimadas las peticiones no resueltas o los recursos no contestados en cierto plazo, al efecto de deducir frente a esta denegación presunta el correspondiente recurso, administrativo o jurisdiccional, según proceda $^{12}$. 
Precisamente, uno de los problemas hasta ahora no superados en la administración pública de nuestro país, es la demora para obtener un pronunciamiento de ellos; y en tanto no se logre ese pronunciamiento, la ejecución de la actividad para la cual solicitaba la autorización tendrá que esperar la buena voluntad de la administración con la consecuente afectación económica para quien requiere de ese pronunciamiento previo, como parte del control previo estatal. Frente a ello, la técnica del silencio administrativo, ya consagrada en la LPAG, se presenta como una de las formas para enfrentar la lentitud de la administración pública ${ }^{13}$.

Morón ${ }^{14}$ considera que en el ámbito de las relaciones entre el administrado y las entidades públicas, la no manifestación oportuna de voluntad de la entidad (silencio) es considerado un hecho administrativo al cual le sigue un tratamiento de declaración ficta. Así, la discusión no se centra respecto a si la omisión de declaración conduce o no a una declaración de voluntad, como sucede en el derecho privado, sino respecto al sentido de esta declaración de voluntad aparentemente dispuesta por la ley, y respecto a cuáles son los presupuestos básicos para su acogimiento.

En nuestro país, la Ley N 29060, Ley del Silencio Administrativo, regula esta posibilidad a través del silencio positivo y negativo. El negativo, genera una situación jurídica a favor del peticionante; mientras el positivo, da lugar al nacimiento de un acto administrativo. La ley otorga al silencio administrativo negativo el carácter de un instrumento procesal y al silencio administrativo positivo los efectos de una declaración con el sentido que la ley le atribuye ante el silencio ${ }^{15}$.

El silencio negativo consiste en que transcurrido el plazo establecido en la ley para que la administración se pronuncie, el afectado pueda considerar denegado su pedido y acudir a la instancia superior hasta agotar la vía administrativa. Incluso por este mecanismo se le permite satisfacer la exigencia de agotar la vía administrativa y puede validamente acceder al control judicial de los actos de la administración pública, mediante la demanda contencioso administrativa.

El Tribunal Constitucional así lo ratifica en el pronunciamiento emitido en la STC No 1003-98-AA/TC (caso Alarcón Menéndez) "habiendo transcurrido, el plazo en exceso sin que la administración se haya pronunciado por la solicitud del demandante, ha operado el silencio administrativo negativo, por lo que el recurrente de acuerdo al artículo $188^{\circ}$, numeral $188^{\circ} .3$ de la Ley $\mathrm{N}^{\circ}$ 27444, se encuentra habilitado para interponer los recursos administrativos y las actuaciones judiciales pertinentes..."16 
Es importante precisar que este silencio opera, luego de vencido el tiempo concedido a la administración pública para que se pronuncie en cada caso concreto, esto es, abre un nuevo espacio de tiempo en el cual el peticionante puede, en cualquier momento y a su sola voluntad, decidir acudir a la instancia superior correspondiente. Mientras el particular no ejerza la facultad, la administración pública sigue obligada a la emisión del pronunciamiento e incluso puede ser objeto de una queja para establecer su nivel de responsabilidad disciplinaria y ser obligada a efectuar el pronunciamiento. La administración mantiene la obligación de resolver hasta que se le notifique que el asunto se ha sometido al conocimiento de la autoridad jurisdiccional o el administrado haya hecho uso de los recursos respectivos. La ventaja de esta técnica se aprecia en que el peticionante queda facultado a decidir si hace valer la técnica del silencio administrativo negativo o espera la emisión del acto, pudiendo incluso forzar dicha emisión a través de la queja.

El silencio administrativo está limitado en su aplicación a determinados casos, como lo señala la Primera Disposición Transitoria, Complementaria y Final de la Ley $\mathrm{N}^{\circ} 29060^{17}$. El informe de la Defensoría del Pueblo $\mathrm{N}^{\circ} 145^{18}$ sobre el particular expresa que cuando el procedimiento importe una afectación significativa al interés público, las autoridades deben tener mucho cuidado en la calificación, a fin de aplicarlo a aquellos casos que sí expongan significativamente el interés público, debiendo entenderse por interés público aquello que trasciende el estricto ámbito de los intereses de los particulares destinatarios del acto. "Así por ejemplo, si ante un requerimiento efectuado ante Sedapal por las filtraciones de aguas externas hacia el predio, cabría aplicar el SAP, lo mismo sucedería en un procedimiento de recepción, evaluación y custodia de medicamentos sujetos a fiscalización sanitaria por cierre o clausura de laboratorio, o en un procedimiento medio ambiental, relacionado con el procedimiento de inscripción de consultoras para Evaluación de Impacto Ambiental (EIA). También se encuentran en este rubro aquellos procedimientos en los que por tratarse de bienes o recursos escasos no resulta aplicable el SAP, como son los procedimientos en los que se transfieren facultades a la administración pública (concesiones, delegación de atribuciones) o en los que generan una obligación de hacer o dar del Estado (el pago de acreencias, compensaciones de deudas, indemnizaciones, etc). Asimismo, se aplica el SAN en aquellos procedimientos trilaterales en los que, debido a la inercia de la autoridad, no se puede beneficiar a una de las partes en perjuicio de la otra y en los procedimientos en los que por seguridad jurídica, deben concluir con una inscripción o con una declaración desestimatoria (tacha, observación, etc.)"19. 
El silencio positivo administrativo opera luego de vencido el tiempo concedido a la administración pública para que se pronuncie en cada caso concreto, da lugar al nacimiento de un acto administrativo. La plenitud del acto administrativo que nace del silencio administrativo está fuera de toda discusión y, precisamente por ello, pone fin al procedimiento administrativo, no siendo necesario que la administración pública emita el pronunciamiento expreso. Aquí, el peticionante no tiene opción alguna de esperar el pronunciamiento expreso, pues, una vez vencido el plazo, solo le resta hacer valer el acto administrativo generado mediante este mecanismo legal.

El silencio positivo, es una técnica mas reciente y es apreciado como una especie de sanción a la administración pública cuando incurre en retardo en el cumplimiento de sus funciones y como remedio para el solicitante que no obtiene un pronunciamiento de aprobación de su pedido.

Véase -a manera de ilustración de cómo opera este silencio- el siguiente caso que acoge el Informe Defensorial N ${ }^{\circ} 145$ : "La Asociación cuestionó que la municipalidad habría desconocido la licencia de funcionamiento que la denunciante obtuvo por aplicación del SAP. La municipalidad declaró improcedente su solicitud de licencia, motivo por el cual el denunciante interpuso un recurso de reconsideración contra dicha resolución. Sin embargo, dicho recurso no fue resuelto dentro de los (30) treinta días que establece el artículo $207^{\circ}$ de la LPAG, por lo que el denunciante se acogió al SAP. La Comisión constató que el recurso de reconsideración interpuesto por el denunciante no fue resuelto por la municipalidad dentro de los (30) días que establece la Ley, por lo que se consideró que se debía entender como revocada la resolución que declaró improcedente su solicitud de licencia y, por tanto, entenderse como otorgada. Sin embargo, precisó que ello no desconoce las atribuciones de control posterior que posee la municipalidad para verificar la autenticidad de las declaraciones y documentos proporcionados por el administrado en su solicitud, pudiendo, de ser el caso, solicitar la revocación del acto y demás consecuencias establecidas en la LPAG"20.

Esta técnica no deja de tener algunas debilidades para su cuestionamiento, como la vinculada con la prueba del acto en el mundo jurídico. Para Rojas ${ }^{21}$, "en un país donde la cultura del papel escrito es todavía predominante y donde la acreditación pasa por un alto contenido en la veracidad de los hechos afirmados por el declarante, la prueba es fácilmente descartada por cualquier inspector o funcionario público; otra debilidad la ubicamos en los alcances del silencio frente a terceros y en el hecho de que el silencio positivo requiere de conocimientos jurídicos del solicitante, pues, a este le corresponderá eva- 
luar la legalidad de lo pedido y de lo autorizado por el silencio, pues, podría existir el riesgo de que el pedido sea contrario al ordenamiento jurídico, y por tanto, nula dicha decisión. Es el propio peticionante quien tendrá que evaluar la legalidad del acto obtenido por silencio administrativo positivo y asumir las consecuencias de ejecutar o no la supuesta facultad o derecho que lo habrían beneficiado mediante la aplicación de esta técnica. Como dice Rojas ${ }^{22}$, "Por la vía del silencio administrativo positivo, no se podría generar un acto administrativo válido si lo que fue objeto del pedido no guarda correspondencia con el ordenamiento jurídico. Un pedido ilegal no da lugar a un acto administrativo válido, ya sea que dicho acto tenga la condición de expreso o haya sido obtenido por la vía del silencio administrativo positivo" 23 .

\section{LA TUTELA JURISDICCIONAL EFECTIVA DE LOS DERECHOS DE LOS ADMINISTRADOS - TENDENCIAS ACTUALES EN EL DISTRITO JUDICIAL DE LIMA}

Hasta hace poco, la administración gozaba del privilegio de exigir que cualquier discrepancia con sus decisiones se ventile en sede administrativa ante sus propios órganos jerárquicos superiores, como condición previa a la interposición de la demanda judicial. Esta especial condición se veía distorsionada por una anquilosada práctica orientada a dilatar el agotamiento de la vía administrativa, de tal manera, que se evitaba deliberadamente que la decisión cause estado, limitando así el derecho a hacer valer la tutela judicial efectiva. En otras palabras, bastaba que la actividad administrativa no sea diligente en su pronunciamiento, para que toda la secuencia del procedimiento, se paralizare y con mayor razón el control jurisdiccional no prospere.

Ante las vicisitudes de la administración estatal, se hace necesario replantearse el contencioso como cauce de solución a conflictos jurídicos que surgen en relación con un asunto jurídico público. El contencioso administrativo se configura como una manifestación más de la genérica función jurisdiccional que tiene como fin primordial tutelar situaciones jurídicas intersubjetivas, reestablecimiento de la integridad de los derechos eintereses de los ciudadanos. La conexión entre el titular de uno de esos derechos e intereses y el proceso subsiguiente es la pretensión.

Ella desplaza al acto administrativo como elemento determinante de la legitimación: legitimado no está el destinatario de la actuación administrativa, ni siquiera el afectado por dicha actuación; legitimado está quien ha sufrido o teme sufrir una lesión de cualquier derecho o interés protegible y pretende el auxilio de los jueces. 
Bajo esa perspectiva, apreciamos un nuevo comportamiento de los peticionantes en sede administrativa cuando trasladan sus conflictos a sede judicial. Hay un incremento vertiginoso en estos últimos años de las pretensiones contencioso administrativas, a tal punto que en los juzgados del distrito judicial de Lima encontramos que la carga procesal ha crecido aceleradamente, como se muestra en el cuadro 01 y 02 que se presentan a continuación.

De los 2 juzgados contenciosos que albergaban una carga procesal de 5,042 expedientes en el año 2003; a mayo del 2009, dicha carga se ha incrementado a 45, 881 expedientes con el aumento a 27 juzgados especializados en el conocimiento de materias contenciosas. Esto que no es una novedad, porque también ello se viene apreciando en experiencias foráneas, como la que cita González Pérez ${ }^{24}$, no significa que "se haya mejorado tanto la imagen de la justicia que los miles de ciudadanos acudan a los órganos judiciales en demanda de justicia"; considero que ello no es así, sino que es tan descomunal la confrontación en sede administrativa entre el administrado y la administración, que se busca aceleradamente desequilibrar ese poder y los efectos generados por éste, a través de sus actos administrativos, ante la justicia ordinaria.

Unelementoquecontribuyeaese trasladodeladiscusión desedeadministrativa a sede judicial es la búsqueda de la tutela de la jurisdicción, en atención a que las pretensiones contenciosas no están en función del acto administrativo ni tampoco están condicionadas al contenido de dicho acto. La intervención judicial no puede verse obstaculizada ni limitada por la administración. A ella se le brinda la oportunidad de pronunciarse previamente a que la jurisdicción haga su obra, ya sea para declarar la nulidad del acto o dar plena tutela cuando se vulnere o dañe intereses legítimos de los administrados.

Como se podrá apreciar, el centro de gravedad en el contencioso administrativo, ya no es el acto administrativo en sí, sino los intereses subjetivos de los ciudadanos que se enfrentan a la administración pública, para lo cual, nuestro sistema jurídico contempla diversas vías para resarcir necesidades y brindar protección judicial. En ese camino, la Ley del Silencio Administrativo, es un excelente instrumento que privilegia la posición del administrado frente a la administración para protegerlo frente a la mora. Con esto se busca crear situaciones jurídicas a favor del peticionante en caso la administración no actúe pronto o haga omisión de ella. La ley sustituye la voluntad administrativa inexistente para presumir determinados efectos, como el nacimiento de un acto administrativo o la situación jurídica a favor del peticionante. 
Como se dice, la no manifestación de voluntad crea un hecho administrativo a través de la declaración ficta. En ese marco, resulta interesante apreciar los criterios esbozados por los jueces de las diversas instancias del contencioso administrativo en el Pleno Jurisdiccional Regional de Setiembre del 2009. En él se plantearon algunas ponencias vinculadas con la posibilidad de que el juez supere el principio de congruencia procesal y otorgue en la sentencia mayor derecho o cosa distinta a la peticionada ${ }^{25}$. Frente a ello, el Pleno adoptó -por mayoría- la posición de que "el juez del proceso contencioso administrativo, dentro de la concepción del proceso como de tutela subjetiva plenaria, y en observancia a la finalidad del PCA prevista en el artículo $1^{\circ}$ del TUO de la Ley $\mathrm{N}^{\circ} 27584$, puede disponer o adoptar, en la sentencia, o con posterioridad a su emisión, las medidas que sean necesarias para que la sentencia estimatoria sea eficaz para el administrado" ${ }^{26}$. Como se puede inferir, la tutela va más allá del acto administrativo, supera el concepto clásico de revisión vía recurso, para ingresar a un conocimiento pleno, sin estar condicionado por el acto administrativo impugnado.

\section{Cuadro $\mathrm{N}^{\circ} 01$ \\ Comportamiento Acumulado \\ Juzgados contencioso administrativos - Distrito Judicial de Lima}

\begin{tabular}{|c|r|r|c|}
\hline Año & Ingresos & Egresos & Carga Pendiente \\
\hline 2003 & 3716 & 938 & 5042 \\
\hline 2004 & 9056 & 6920 & 8646 \\
\hline 2005 & 12534 & 11590 & 11730 \\
\hline 2006 & 47696 & 32220 & 28928 \\
\hline 2007 & 18518 & 9426 & 32920 \\
\hline 2008 & 27002 & 29357 & 28777 \\
\hline $2009^{* *}$ & 7759 & 6952 & 29584 \\
\hline Sub-Total & $\mathbf{1 2 6 2 8 1}$ & $\mathbf{9 7 4 0 3}$ & $\mathbf{2 9 5 8 4}$ \\
\hline $2008^{*}$ & 20626 & 3230 & 18716 \\
\hline $2009^{*}$ & 215 & 2630 & 16297 \\
\hline Total & $\mathbf{1 4 7 1 2 2}$ & $\mathbf{1 0 3 2 6 3}$ & 45881 \\
\hline
\end{tabular}

* Juzgados Transitorios.

** Hasta mayo del 2009.

Fuente: Oficina de Apoyo a la Presidencia Corte de Lima

Elaboración propia 


\section{Cuadro $\mathrm{N}^{\circ} 02$}

Comportamiento Acumulado por Número de Dependencias Juzgados contencioso administrativos

Distrito Judicial de Lima

\begin{tabular}{|c|r|r|c|}
\hline N. $^{\circ}$ Dependencias & Ingresos & Egresos & $\begin{array}{c}\text { Egresos/ } \\
\text { Ingresos }{ }^{* 100}\end{array}$ \\
\hline 2 & 7033 & 4358 & 61.97 \\
\hline 4 & 23045 & 18061 & 78.37 \\
\hline 8 & 40626 & 28564 & 70.31 \\
\hline 10 & 14443 & 5764 & 39.91 \\
\hline 15 & 35901 & 35356 & 98.48 \\
\hline $17^{* *}$ & 5233 & 5300 & 101.28 \\
\hline Sub-Total & $\mathbf{1 2 6 2 8 1}$ & $\mathbf{9 7 4 0 3}$ & $\mathbf{7 7 . 1 3}$ \\
\hline $10^{*}$ & 20841 & 5860 & 28.12 \\
\hline Total & $\mathbf{1 4 7 1 2 2}$ & $\mathbf{1 0 3 2 6 3}$ & $\mathbf{7 0 . 1 9}$ \\
\hline
\end{tabular}

\footnotetext{
* Juzgados Transitorios

*** Hasta mayo del 2009

Fuente: Oficina de Apoyo a la Presidencia Corte de Lima

Elaboración propia
}

\section{CONCLUSIONES}

5.1. La función jurisdiccional contencioso administrativa se concibe como una función judicial resolutoria de conflictos y no necesariamente revisora de actos administrativos.

5.2. La presencia de un acto administrativo no es consustancial a la existencia del proceso, simplemente debe ser un punto de referencia para definir el acceso a la jurisdicción contenciosa administrativa.

5.3. El proceso contencioso administrativo encierra una función jurisdiccional, para la efectiva tutela de los derechos e intereses legítimos de la administración y de los administrados, en él se ventilan situaciones conflictivas entre partes en igualdad procesal. Esa es la gran fortaleza que se esgrime en este tipo de pretensiones, donde se busca atenuar o contrarrestar, en un escenario imparcial, el desequilibrio entre la fuerza y el poder de la administración frente a los administrados. 
1 Priori Posada, Giovanni. Comentarios a la Ley del Proceso Contencioso Administrativo. $3^{\circ}$ ed. Lima: Ara editores, 2006, p.122.

2 Esta posición era recogida en nuestra legislación en el Código Procesal Civil, cuando regulaba el procedimiento a seguir en el contencioso-administrativo. Decía el artículo $540^{\circ}$ C.P.C. "la demanda contencioso administrativa se interpone contra el acto o resolución de la administración a fin que se declare su invalidez o ineficacia. Se excluyen aquellos casos en que la Ley, expresamente, declara inimpugnable lo resuelto por la autoridad administrativa". Esta regulación evidentemente determinó que se asumiera la posición de que el objeto del contencioso administrativo era el control de legalidad del acto y que la labor del Poder Judicial se veía restringida a ello, sin que pudiera pronunciarse sobre el fondo de la decisión administrativa.

3 Huapaya Tapia, Ramón. Tratado del proceso contencioso administrativo. Lima: Jurista, 2006, p. 67.

4 Priori Posada, Giovanni, Ob. Cit., p. 55.

5 García Pérez, María. El objeto del proceso contencioso-administrativo. Pamplona: Aranzadi, 1999, p. 55.

6 Ante ello, la doctrina procesal administrativa afirma la concurrencia de dos tipos de pretensiones en el contencioso administrativo, la pretensión de anulación o de nulidad y la pretensión de plena jurisdicción. En el primer caso, dice Priori "el particular acude al órgano jurisdiccional con la finalidad de que este realice un control de legalidad de una actuación administrativa, con la particularidad que la competencia del órgano jurisdiccional se limitará a realizar una declaración de nulidad de la actuación administrativa impugnada. Es por ello que en este caso nos encontramos ante una pretensión meramente declarativa. En el caso de la pretensión de plena jurisdicción es un reconocimiento, a nivel del proceso contencioso administrativo, del derecho a la tutela jurisdiccional efectiva, pues, a través de ella, el particular puede obtener un pronunciamiento jurisdiccional que de manera real y eficaz le proporcione una tutela a las situaciones jurídicas de las cuales es titular. De esta forma, se solicita al órgano jurisdiccional no solo la anulación del acto, sino el reconocimiento de una situación jurídica individualizada y la adopción de las medidas adecuadas para el pleno restablecimiento de la misma, entre ellas, la indemnización de daños y perjuicios, cuando proceda". Ob. Cit., pp. 122-123.

7 Priori Posada, Giovanni, Ob. Cit., p. 56.

8 Sentencia No 2802-2005-AA/TC. Caso Julia Mabel Benavides García. Fecha de publicación 12/12/2005. Fundamento 16. Disponible en internet: http://www.tc.gob.pe/jurisprudencia/2005/02802-2005-AA.html.

9 Precedentes Constitucionales. Sentencia Nº 1417-2005-PA/TC. Caso Manuel Anicama Hernández. Fecha de publicación 11/07/2005

10 STC No 815-2004-AA/TC del 25 de junio del 2004. Caso Paulino Núñez Cabreras; STC No 4077-2004-AA/TC del 21 de junio del 2005, Caso María del Pilar Gularte Unyén.

11 García Perez, María, Ob. Cit., p. 58.

12 Es en esa misma línea, léase: "Es importante precisar que el sentido del silencio administrativo es el de servir de garantía al administrado en los procedimientos de evaluación previa, de modo que ante una inacción de la administración, aquel tenga la posibilidad de accionar los medios impugnatorios correspondientes, impulsando el procedimiento, o poder entender otorgado el derecho o concedido el pedido, según se trate de silencio administrativo negativo o positivo, respectivamente". Pando Vilchez, Jorge. El doble silencio administrativo ipuede ser negativo? Disponible en internet: http://www.congreso.gob.pe/juridica/documentos/ DOBLE_SILENCIO_ADMINISTRATIVO_NEGATIVO.PDF. Setiembre. 2009.

13 Los antecedentes de esta técnica lo ubicamos en la experiencia francesa de principios del siglo XX. Dice Rojas Leo, Juan Francisco "Los franceses se encontraban preocupados porque los funcionarios de la administración pública utilizaban el retardo en la expedición del pronunciamiento, o incluso omitían pronunciarse sobre los recursos impugnativos planteados a sus decisiones, de manera tal, que no fuera posible agotar la vía administrativa y, consiguientemente, la controversia no pudiera ser llevada a la vía judicial" "El silencio administrativo positivo y las debilidades de una ilusión, a propósito de la promulgación de la Ley N²9060". En: JUS, doctrina \& práctica. $\mathrm{N}^{\circ} 7,2007$, julio, Grijley, p. 28; en esa misma línea de referencia, léase el Informe de la Defensoría del Pueblo, $\mathrm{N}^{\circ} 145,2009$, p. 25.

14 Morón Urbina, Juan Carlos. Comentarios a la Ley del Procedimiento Administrativo General. $7^{\circ}$ ed. Lima: Gaceta Jurídica, 2008, pp. 843-844.

15 La distinción ha sido objeto de tratamiento normativo en el artículo 188 ${ }^{\circ}$ LPAG: 188.1 .- Los procedimientos administrativos sujetos a silencio administrativo positivo quedarán automáticamente aprobados en los términos en que fueron solicitados si transcurrido el plazo establecido o máximo la entidad no hubiera comunicado al administrado el pronunciamiento (positivo); 188.2 El silencio administrativo tiene para todos los efectos el carácter de resolución que pone fin al procedimiento, sin perjuicio de la potestad de nulidad de oficio, prevista en el artículo $202^{\circ}$ de la presente Ley; 188.3 .- El silencio administrativo negativo tiene por efecto habilitar al administrado la interposición de los recursos administrativos y acciones judiciales pertinentes; 188.4 .- Aun cuando opere el silencio administrativo negativo, la administración mantiene la obligación de resolver bajo responsabilidad, hasta que se le notifique que el asunto ha sido sometido a conocimiento de una autoridad jurisdiccional o el administrado haya hecho uso de los recursos administrativos respectivos. 
${ }_{16}$ Caso citado por el Informe de la Defensoría del Pueblo $N^{\circ} 145$, Aplicación del silencio administrativo: retos y tareas pendientes. Lima, 2009, p. 8.

$171^{\circ}$ Disposición T, C y F - Silencio Administrativo Negativo Excepcionalmente: el silencio administrativo negativo será aplicable en aquellos casos en los que se afecte significativamente el interés público, incidiendo en la salud, el medio ambiente, los recursos naturales, la seguridad ciudadana, el sistema financiero y de seguros, el mercado de valores, la defensa comercial, la defensa nacional y el patrimonio histórico cultural de la nación; en aquellos procedimientos trilaterales y en los que generen obligación de dar o hacer del Estado; y autorizaciones para operar casinos de juego y máquinas tragamonedas. Asimismo, será de aplicación para aquellos procedimientos por los cuales se transfiera facultades de la administración pública, y en aquellos procedimientos de inscripción registral.

18 Informe Defensorial, Ob. Cit., pp. 88-89

19 Informe Defensorial, Ob. Cit., pp. 89

${ }^{20}$ Caso: Asociación Club Tenis San Miguel contra la Municipalidad Distrital de San Miguel. Resolución No 0220-2008/CEB-INDECOPI del 14 de noviembre del 2008, citado por la Defensoría de Pueblo, Infome Defensorial $\mathrm{N}^{\circ} 145$, Ob. Cit., p. 135

${ }^{21}$ Rojas, Ob. Cit., p. 30.

22 Rojas, Ob. Cit., p.29.

${ }^{23}$ Esta situación ha sido recogida en el inciso 3 del artículo $10^{\circ}$ de la LPAG que dice: "son vicios del acto administrativo que causan su nulidad de pleno derecho, los siguientes: (...) $3^{\circ}$ Los actos expresos o los que resulten como consecuencia de la aprobación automática o por silencio administrativo positivo, por los que se adquiere facultades, o derechos, cuando son contrarios al ordenamiento jurídico, o cuando no se cumplen con los requisitos, documentación o trámites esenciales para su adquisición". Con este enunciado se busca eliminar la posibilidad de osados peticionantes de la administración pública, que esperan con mucha expectativa la demora en el pronunciamiento, para convertir un pedido ilegal en un acto legal por obra del silencio administrativo positivo. Jamás la inacción de la administración pública podrá transformar un acto de por sí ilícito como un acto válido.

${ }^{24}$ Cuando al comenzar el siglo XXI contemplamos el fenómeno del impresionante auge de la litigiosidad, con el consiguiente aumento del trabajo que padecen los tribunales, que deriva en verdaderas situaciones de colapso de la Administración de justicia, podría pensarse, ¿ha mejorado tanto la imagen de la Justicia que puede deslumbrar de tal modo a tantos y tantos miles de ciudadanos que acuden a los órganos judiciales en demanda de justicia? ¿Es tanta la confianza en ellos que no dudan en incoar los procesos aun a conciencia de que no obtendrán sentencia firme sino después de muchos años de litigio? Las estadísticas demuestran justamente lo contrario. Reflejan no solamente que la administración de justicia ocupa uno de los lugares más bajos de la escala de "confianzas populares", sino que muy alto porcentaje de ciudadanos dudan de su independencia y tienen sensación de desigualdad de trato. González Pérez, Jesús. «El acceso a la jurisdicción contenciosaadministrativa». En: Ponencia presentada en el Seminario Internacional de Derecho Procesal, Proceso y Constitución. Facultad de Derecho Pontificia Universidad Católica del Perú. 22 al 25 de setiembre. Lima, 2009 (en prensa).

${ }^{25}$ Las ponencias que se presentaron al respecto fueron las siguientes: Primera ponencia: El juez del PCA debe sujetarse, al sentenciar, a lo estrictamente formulado en el petitorio de la demanda, independientemente de la pretensión que se haya postulado. En consecuencia, no puede otorgar mayor derecho o cosa distinta a la peticionada. Segunda ponencia: El juez del PCA, dentro de la concepción del proceso como de tutela subjetiva plenaria, y en observancia a la finalidad del PCA prevista en el artículo $1^{\circ}$ del T.U.O. de la Ley $\mathrm{N}^{\circ} 27584$, puede disponer o adoptar, en la sentencia, o con posterioridad a su emisión, las medidas que sean necesarias para que la sentencia estimatoria sea eficaz para el administrado.

26 El fundamento de esta conclusión, es tanto porque la misma ley lo establece, como por tutela jurisdiccional efectiva; debiendo tenerse presente la circunstancia de la controversia de un particular (parte débil) frente al Estado. Se trata de armonizar la tutela jurisdiccional efectiva del particular con el derecho de defensa de la entidad estatal, por consiguiente, un criterio de armonización y optimización de ambos principios, consiste en que el operador jurisdiccional puede eventualmente apartarse de lo estrictamente peticionado en los caso accesorios. Sobre este tema, el grupo de trabajo advierte la necesidad que en posteriores reuniones o plenos jurisdiccionales se trabaje específicamente sobre los criterios que se debe tener presente para determinar en qué casos es atendible la flexibilización del principio de congruencia. Así por ejemplo, en el caso de una demanda que solo contiene una pretensión de nulidad de resolución de multa es claro que una sentencia que se limita a declarar la nulidad de una resolución administrativa carece de total utilidad atentando contra la tutela jurisdiccional efectiva, advirtiéndose la necesidad de que la sentencia incluya, al menos, la orden a la entidad, de expedir nueva resolución con arreglo a los considerandos precedentes, siendo discutible (sugerimos que ello sea tratado en posterior reunión) que el operador jurisdiccional pueda sustituirse a la administración ordenando la devolución de la multa pagada. 